Supplement of Solid Earth, 9, 1399-1419, 2018

https://doi.org/10.5194/se-9-1399-2018-supplement

(C) Author(s) 2018. This work is distributed under

the Creative Commons Attribution 4.0 License.

(c) (1)

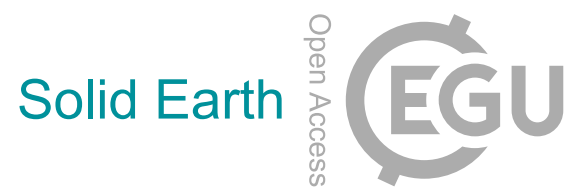

Supplement of

\title{
Myrmekite and strain weakening in granitoid mylonites
}

Alberto Ceccato et al.

Correspondence to: Alberto Ceccato (alberto.ceccato.2@phd.unipd.it)

The copyright of individual parts of the supplement might differ from the CC BY 4.0 License. 


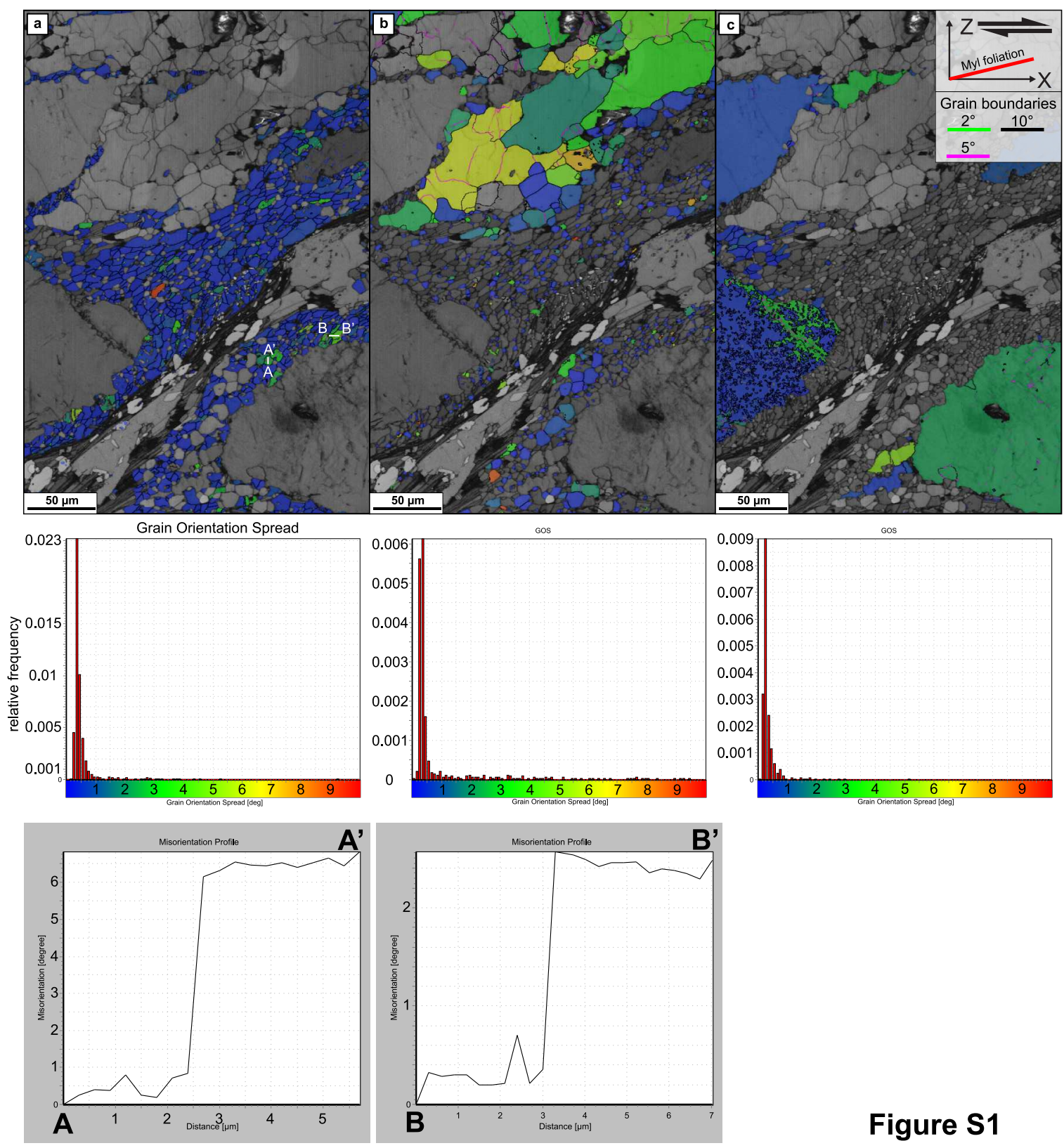




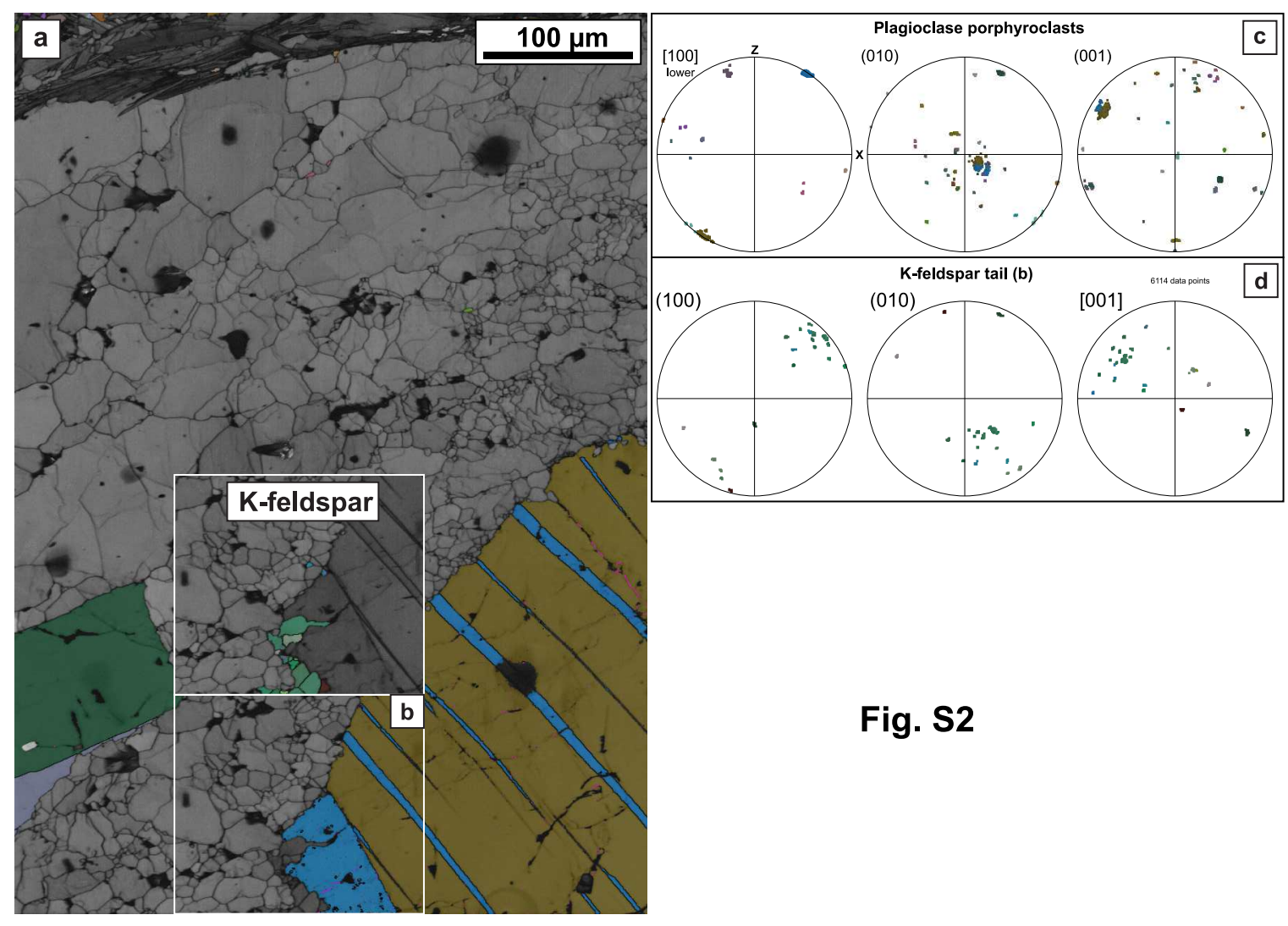




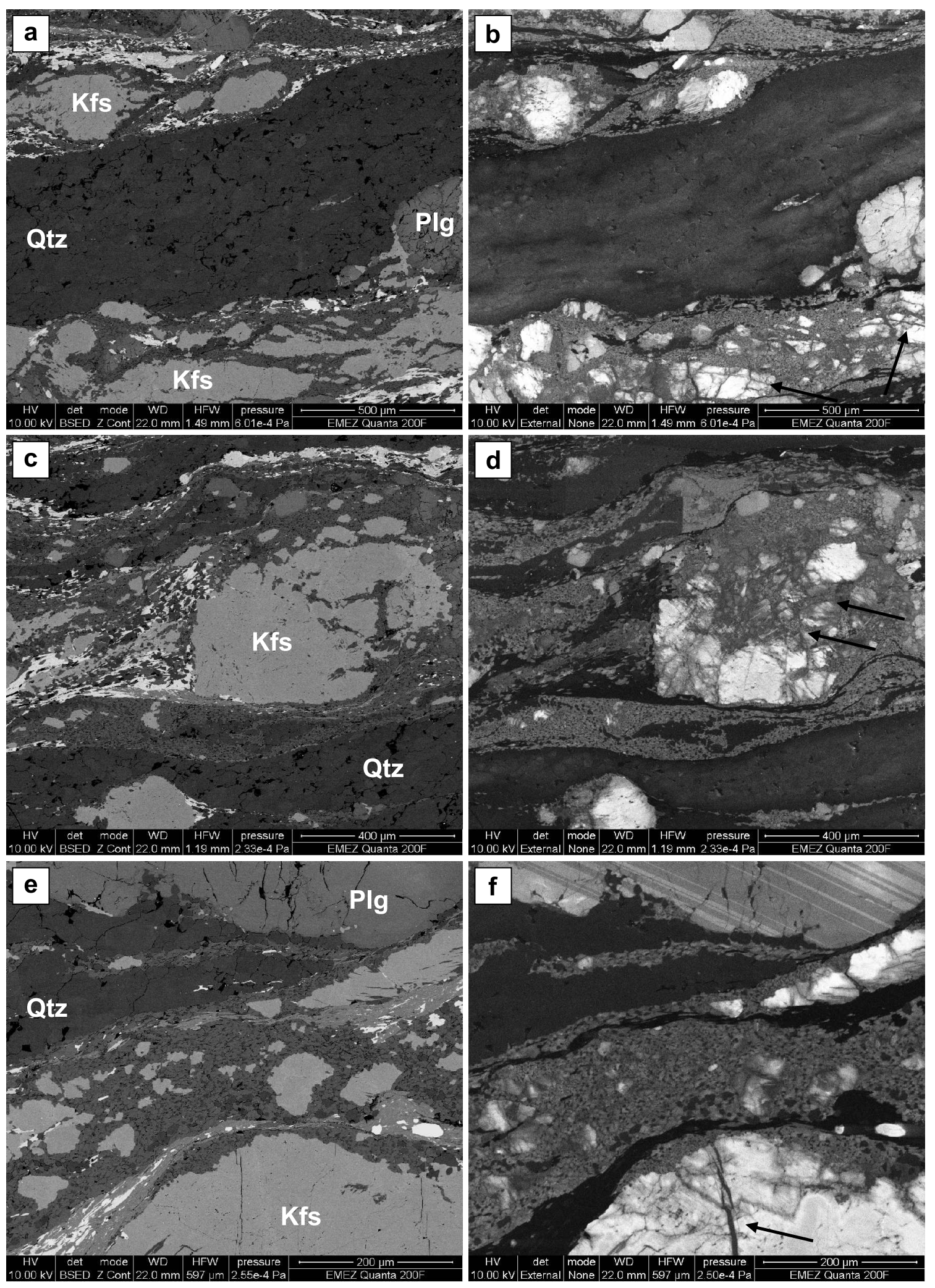

Figure S3 


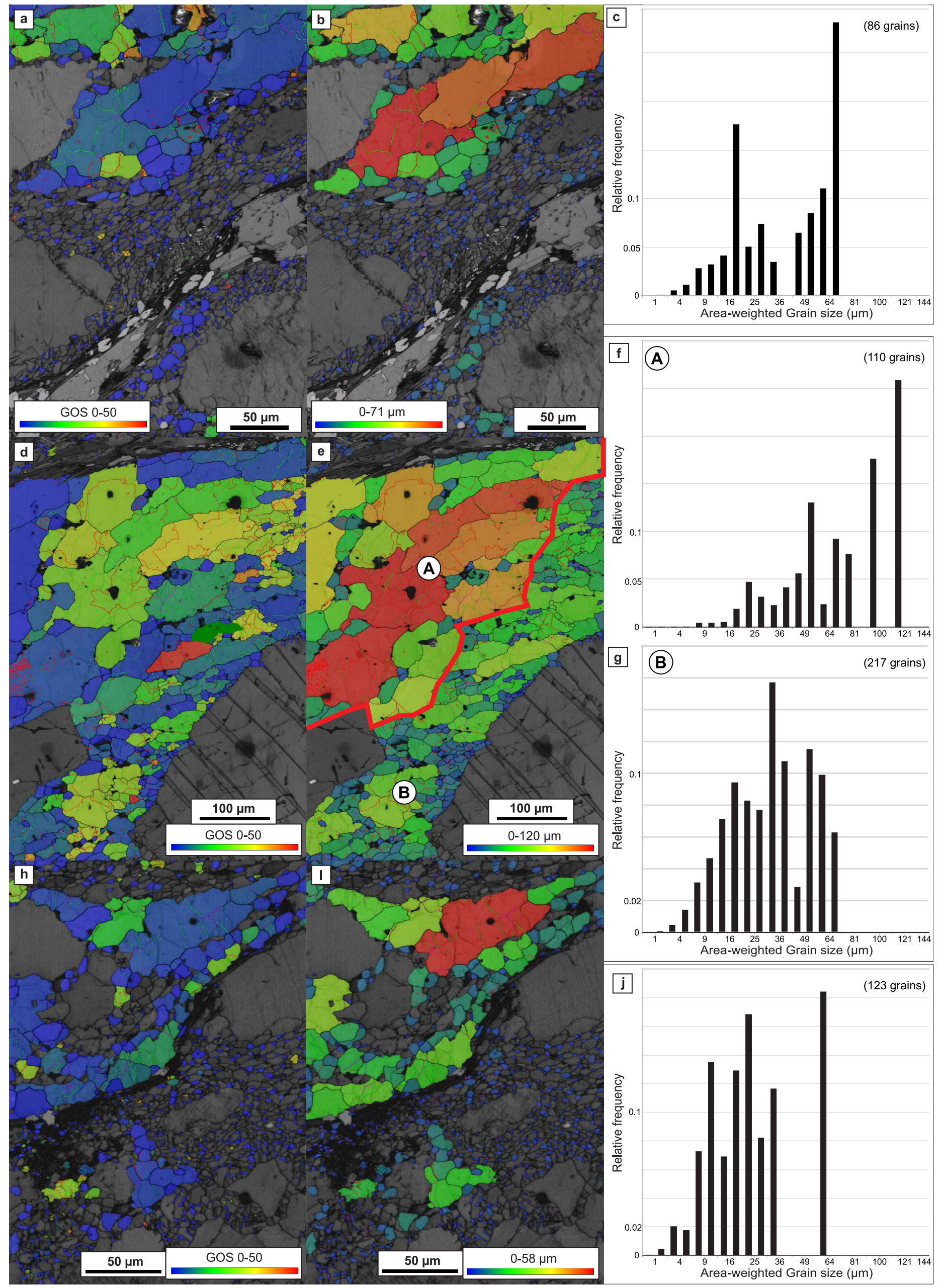

Figure S4 
Figure S1. Grain Orientation Spread (GOS) maps for areas reported in Figs. 4 showing the average orientation spread for each grain of plagioclase (a), quartz (b) and K-feldspar (c) in the related frequency histograms. For (a) two misorientation profile across low-angle boundaries in plagioclaseare reported to show the limited internal distortion of plagioclase grains and the abrupt change in orientation across the analysed low-angle boundary.

Figure S2. EBSD orientation maps for K-feldspar and plagioclase. (a) Orientation map for Plagioclase and (b) K-feldspar. (c) Pole figures reporting the crystallographic orientation of plagioclase porphyroclast. (d) Pole figures reporting the crystallographic orientation of K-feldspar tail.

Figure S3. Backscattered and Cathodoluminescence images of Rieserferner mylonites. (a) BSE image of pure quartz layers (Qtz) between two sheared K-feldspar-myrmekite (Kfs) aggregate. (b) CL image of (a). Note the homogeneous signature of quartz and the complex microstructure of K-feldspar aggregate and porphyroclasts (indicated by black arrows). (c) BSE image of a K-feldspar aggregate enveloped by sheared myrmekite. The top-left corner of the K-feldspar grain is reported in the EBSD map of Fig. 3. (d) CL image of (c). Note the complex pattern of low-grey CL shades of Kfeldspar aggregate (indicated by black arrows). (e) K-feldspar aggregate and sheared myrmekite. (f) CL image of (e). Note the complex pattern of low-grey CL shades of K-feldspar aggregate (indicated by black arrows).

Figure S4. Grain size and GOS maps for EBSD maps reported in Fig. 4, SOM2, 3, respectively, and relative quartz grain size distributions. (a) (b) (c) Grain size, GOS maps and grain size distribution for map reported in Fig. 6. (d) (e) (f) (g) Grain size, GOS maps and grain size distribution for map reported in Fig. SOM2. (h) (i) (j) Grain size, GOS maps and grain size distribution for map reported in Fig. 3. 


\section{Derivation of the deformation mechanism maps and aggregate flow laws.}

The bulk strain rate $\left(\dot{\varepsilon}_{\text {bulk }}\right)$ of a mineral aggregate is given by:

$$
\dot{\varepsilon}_{\text {bulk }}=\dot{\varepsilon}_{\text {Disl }}+\dot{\varepsilon}_{\text {Diff }}
$$

where: $\dot{\varepsilon}_{\text {Disl }}$ and $\dot{\varepsilon}_{\text {Diff }}$ represents the strain rates of dislocation creep and diffusion creep of mineral components, respectively.

Quartz. The deformation mechanisms map of Fig. 9a has been calculated as follows. The flow law of Hirth et al. (2001) has been used to calculate the contribution of dislocation creep of quartz:

$$
\dot{\varepsilon}_{q-D i s l}=A_{q} f_{h} \sigma^{n} e^{\left(-\frac{Q q}{R T}\right)}
$$

where: $A_{q}$ is the pre-exponential factor for quartz $\left(\mathrm{MPa}^{-\mathrm{n}} \mathrm{s}^{-1}\right) ; f_{\mathrm{h}}$ is the water fugacity; $\sigma$ is the differential stress $(\mathrm{MPa}) ; n$ is the stress exponent; $Q_{q}$ is the activation energy $(\mathrm{J}) ; R$ is the gas constant $\left(\mathrm{J} / \mathrm{K}^{*} \mathrm{~mol}\right)$; $T$ is the temperature (K). Following Platt (2015), the flow law of den Brok (1998) for thinfilm model of pressure-solution has been used to calculate the contribution of pressure-solution to quartz deformation:

$$
\dot{\varepsilon}_{q-D i f f}=\dot{\varepsilon}_{q p s}=C_{2} \frac{\rho_{f}}{\rho_{s}} \frac{\sigma}{d^{3}} \frac{V c D_{w}}{R T}
$$

where: $C_{2}$ is a shape constant; $\rho_{f}$ and $\rho_{s}$ are the fluid and solid densities $\left(\mathrm{Kg} \mathrm{m}^{-3}\right)$, respectively; $d$ is the grain size $(\mu \mathrm{m}) ; V$ is the molar volume $\left(\mu \mathrm{m}^{3} \mathrm{~mol}^{-1}\right) ; c$ is the solubility of the solid in the fluid phase (molar fraction); $D_{w}$ is the diffusivity of the solid in the grain-boundary fluid film $\left(\mu \mathrm{m}^{2} \mathrm{~s}^{-1}\right)$.

Feldspars. The flow laws of Rybacki et al. (2006) have been used to calculate the contribution of dislocation and diffusion creep of feldspar:

$$
\begin{aligned}
& \dot{\varepsilon}=A_{f} f_{h} \frac{\sigma^{n}}{d^{m}} e^{\left(-\frac{Q_{f}+p V^{a c t}}{R T}\right)} \\
& \dot{\varepsilon}_{f-D i s l}=A_{f} f_{h} \sigma^{3} e^{\left(-\frac{Q_{f}+p V^{a c t}}{R T}\right)} \\
& \dot{\varepsilon}_{f-D i f f}=A_{f} f_{h} \frac{\sigma}{d^{3}} e^{\left(-\frac{Q_{f}+p V^{a c t}}{R T}\right)}
\end{aligned}
$$


where: $A_{f}$ is the pre-exponential factor for feldspar $\left(\mathrm{MPa}^{-\mathrm{n}} \mu \mathrm{m}^{\mathrm{m}} \mathrm{s}^{-1}\right) ; d$ is the grain size $(\mu \mathrm{m}) ; m$ is the grain-size exponent ( $m=3$ for diffusion creep; $m=0$ for dislocation creep); $p$ is the confining pressure $(\mathrm{MPa}) ; V^{a c t}$ is the activation volume $\left(\mathrm{m}^{3} \mathrm{~mol}^{-1}\right)$.

Poly-phase aggregates. Deformation mechanism maps and rheological calculations for poly-phase aggregates (feldspar + quartz, i.e. sheared myrmekite and granitoid rock, Fig. 9b-c) were calculated following the self-consistent approach presented in Dimanov and Dresen (2005) and Platt (2015). The flow law for the poly-phase aggregate is the following:

$$
\dot{\varepsilon}_{\text {bulk }}=\dot{\varepsilon}_{\text {Disl }}+\dot{\varepsilon}_{q p s}=A_{a} f_{h} \sigma^{n_{a}} e^{\left(-\frac{Q a}{R T}\right)}+\frac{\sigma}{2 \mu_{a}}
$$

The flow law parameters $A_{a}, n_{a}, Q_{a}$ for the "dislocation creep" component (first term of the equation) are calculated as follows:

$$
\begin{aligned}
& \log _{10} n_{a}=\phi_{1} \log _{10} n_{1}+\phi_{2} \log _{10} n_{2} \\
& Q_{a}=\left[Q_{2}\left(n_{a}-n_{1}\right)-Q_{1}\left(n_{a}-n_{2}\right)\right] /\left(n_{2}-n_{1}\right) \\
& \log _{10} A_{a}=\left[\log _{10} A_{2}\left(n_{a}-n_{1}\right)-\log _{10} A_{l}\left(n_{a}-n_{2}\right)\right] /\left(n_{2}-n_{1}\right)
\end{aligned}
$$

where: $n_{a}$ is the stress exponent for the two-phase mixture; $\phi_{i}$ is the volume fraction of the phase $\mathrm{i} ; n_{i}$ is the stress exponent of the $i$ phase; $Q_{a}$ is the dislocation creep activation energy for the aggregate $(\mathrm{J}) ; Q_{i}$ is the activation energy for the $i$ phase $(\mathrm{J}) ; A_{a}$ is the pre-exponential factor for the aggregate $\left(\mathrm{MPa}^{-\mathrm{n}} \mu \mathrm{m}^{\mathrm{m}} \mathrm{s}^{-1}\right) ; A_{i}$ is the pre-exponential factor for the $i$ phase $\left(\mathrm{MPa}^{-\mathrm{n}} \mu \mathrm{m}^{\mathrm{m}} \mathrm{s}^{-1}\right)$. In order to account for water fugacity and activation volumes parameters in feldspar flow laws (Rybacki and Dresen, 2006), we implemented the model of Platt (2015), which includes the activation volume for feldspars in the calculation of the aggregate activation energy $Q_{a}$, as follows:

$$
Q_{a}=\left[\left(Q_{f}+p V^{a c t}\right)\left(n_{a}-n_{Q}\right)-Q_{Q}\left(n_{a}-n_{f}\right)\right] /\left(n_{f}-n_{Q}\right)
$$

where: $p$ is the confining pressure (MPa); $V^{a c t}$ is the activation volume for feldspars $\left(\mathrm{m}^{3} / \mathrm{mol}\right)$. Water fugacity coefficients were integrated in the resulting flow law of poly-phase aggregates deforming by dislocation creep:

$$
\dot{\varepsilon}_{\text {Disl }}=A_{a} f_{h} \sigma^{n a} e^{\left(-\frac{Q a}{R T}\right)}
$$

Following the approach of Dimanov and Dresen (2005) and Platt (2015), the second term of the equation representing the contribution of "diffusion creep" has been calculated by considering 
pressure-solution (in quartz) and diffusion creep (in feldspar) to contribute linearly to the bulk viscosity of the aggregate, $\mu_{a}$ :

$$
3 \mu_{a}^{2}+\left[2\left(\mu_{q}+\mu_{f}\right)-5\left(\phi_{q} \mu_{q}+\phi_{f} \mu_{f}\right)\right] \mu_{a}-2 \mu_{q} \mu_{f}=0
$$

where

$$
\mu_{q}=\frac{\sigma}{2 \dot{\varepsilon}_{q p s}}
$$

is the viscosity of quartz deforming via pressure-solution processes calculated following the thin-film model of den Brok (1998); and

$$
\mu_{f}=\frac{\sigma}{2 \dot{\varepsilon}_{f-d i f f}}
$$

is the viscosity of feldspar deforming via diffusion creep.

The rheological modelling of poly-phase aggregates containing more than two rheological phases (e.g. a granitoid composed of plagioclase + quartz + myrmekite, Fig. 9d) has been performed iteratively applying the calculation of Platt (2015). For example, for a mixture composed of $\phi_{X}, \phi_{Y}$ and $\phi_{Z}$ volume fractions of the phases X (plagioclase), Y (quartz), and Z (sheared myrmekite):

(i) Firstly, $n_{X Y}, Q_{X Y}, A_{X Y}$ flow law parameters for the XY two-phase mixture are calculated following equations (8), (9) and (10), adopting the volume fractions $\phi_{X 1}$ and $\phi_{Y 1}$ defined as follows:

$$
\phi_{X 1}=\phi_{X} /\left(1-\phi_{Z}\right) ; \phi_{Y 1}=\phi_{Y} /\left(1-\phi_{Z}\right) \text {. }
$$

(ii) Then for the calculation of the three-phase mixture flow law parameters $n_{X Y Z}, Q_{X Y Z}, A_{X Y Z}$, considering the three-phase mixture as the result of mixing between phases "XY" and $\mathrm{Z}$, volume fractions are recalculated as follow:

$$
\phi_{X Y}=\phi_{X}+\phi_{Y} ; \phi_{Z}=\phi_{Z}
$$

and the parameters are calculated as follow:

$$
n_{X Y Z}=10^{\wedge}\left(\phi_{X Y} \log _{10} n_{X Y}+\phi_{Z} \log _{10} n_{Z}\right)
$$

$$
Q_{X Y Z}=\left[Q_{Z}\left(n_{X Y Z}-n_{X Y}\right)-Q_{X Y}\left(n_{X Y Z}-n_{Z}\right)\right] /\left(n_{Z}-n_{X Y}\right)
$$

$$
A_{X Y Z}=10^{\wedge}\left[\log _{10} A_{Z}\left(n_{X Y Z}-n_{X Y}\right)-\log _{10} A_{X Y}\left(n_{X Y Z}-n_{Z}\right)\right] /\left(n_{Z}-n_{X Y}\right) .
$$


For the calculation of the rheology of an aggregate in which dislocation and diffusion creep contribute in different proportions to the total strain rate (granitoid rock including a variable amount of myrmekite, see Discussion below), a limiting factor $\theta$ has been introduced in equation (7). For example, for an aggregate in which diffusion creep is limited to a specific volume proportion of phases:

$$
\dot{\varepsilon}_{\text {bulk }}=A_{a} f_{h} \sigma^{n_{a}} e^{\left(-\frac{Q a}{R T}\right)}+\theta_{\text {diff }} \frac{\sigma}{2 \mu_{a}}
$$

where $\theta_{\text {diff }}$ represents the volume fraction of the phases undergoing diffusion creep in the aggregate. To consider the progressive transformation of feldspar into myrmekite with increasing strain, differential stress vs. strain rate curves have been calculated for a "granitoid" aggregate with increasing vol\% of myrmekite substituting for feldspar (Fig. 9c). The progression of the reaction is quantified by the reaction progress factor $\chi$. The maximum volume percentage of feldspar substitution has been limited to

$$
\phi_{M A X}=20 \mathrm{vol} \%
$$

the average concentration of $\mathrm{K}$-feldspar in granite and granodiorite. For $\chi=0$ (no myrmekite), the rock is composed of 60 vol\% plagioclase $\mathrm{An}_{100}$ and 40 vol\% quartz. For $\chi>0$, plagioclase $\mathrm{An}_{100}$ (representing K-feldspar) is increasingly replaced by myrmekite. Myrmekite $\phi_{M y r m}$, plagioclase $\phi_{P l g}$ and quartz $\phi_{Q t z}$ volume proportions in the rock are then re-calculated as follows, respectively:

$$
\begin{aligned}
& \phi_{M y r m}{ }^{1}=\chi * \phi_{M A X} \\
& \phi_{P l g}{ }^{1}=\phi_{P l g}-\chi * \phi_{M A X} \\
& \phi_{Q t z}{ }^{1}=\phi_{Q t z}
\end{aligned}
$$

The calculation of the rheology of a granitoid rock with variable amount of sheared myrmekite takes into account the case in which grain size sensitive creep occurs only in sheared myrmekite, whereas granitoid quartz and feldspars deform only by dislocation creep. Therefore, the contribution of diffusion creep to bulk viscosity in equation (21) is proportional to

$$
\theta_{\text {diff }}=\chi * \phi_{M A X}
$$

